\title{
Effect of Helicobacter pylori, black tea and sodium bicarbonate on iron metabolism and MDCK cell survival
}

\author{
D. Hamedi Asl ${ }^{1}$, B. Rahmani ${ }^{1}$, T. Naserpour Farivar ${ }^{2}$, F. Hajmanochehri ${ }^{3}, \underline{\text { A. Peymani }}^{2}$
}

\footnotetext{
${ }^{1}$ Department of Molecular Medicine, Qazvin University of Medical Sciences, Qazvin, Iran

${ }^{2}$ Medical Microbiology Research Center, Qazvin University of Medical Sciences, Qazvin, Iran

${ }^{3}$ Department of Pathology, Qazvin University of Medical Sciences, Qazvin, Iran

Corresponding Address: Amir Peymani, Medical Microbiology Research Center, Qazvin University of Medical Sciences, Qazvin, Iran

Email: a.peymani@gmail.com. Tel: +98-28-33337006

Received: 26 Jul 2018; Accepted: 11 Oct 2018
}

\section{Abstract}

Background: Iron deficiency anemia is the most common nutritional disorder in the world. Diet and Helicobacter pylori infection are among the main causes of this disorder.

Objective: In this study, the effect of black tea extract and sodium bicarbonate with Helicobacter pylori on the genes involved in iron absorption and storage, as well as cell proliferation, were studied.

Methods: Simultaneous cultivation of MDCK and Helicobacter pylori cell lines was performed at concentrations of 10, 20, 40 and $80 \mathrm{~g} / \mathrm{ml}$ of tea extract and 30, 40, 60 and $100 \mathrm{mM}$ sodium bicarbonate at 24 and 48 hours. The effect of treatment on cell survival was investigated by trypan blue staining and expression of $M Y C, T F R C, F T H 1, I R P 2, I R P 1$, and NDRG1 genes by real-time PCR and analyzed by ANOVA and independent T-test.

Findings: There was no significant change in the expression of the genes involved in iron metabolism under the influence of tea, sodium bicarbonate and Helicobacter pylori treatment in MDCK cell line. Upregulation MYC gene expression was observed in the presence of Helicobacter pylori after 24 hours treatment with tea extract, and sodium bicarbonate, and in the absence of Helicobacter pylori upregulation with tea extract after 48 hours $(\mathrm{P}<0.05)$. Also upregulation NDRG1 gene expression was seen after tea extract treatment of cells with or without Helicobacter pylori in both 24 and $48 \mathrm{~h}(\mathrm{P}<0.05)$.

Conclusion: Sodium bicarbonate and tea each one alone didn't not influence iron status. This study suggests that reduction of tea intake could be served as a risk prevention strategy.

Keywords: Iron, Tea, Sodium bicarbonate, Helicobacter pylori

Citation: Hamedi Asl D, Rahmani B, Naserpour Farivar T, Hajmanochehri F, Peymani A. Effect of Helicobacter pylori, black tea and sodium bicarbonate on iron metabolism and MDCK cell survival. J Qazvin Univ Med Sci 2018; 22(5): 36-43. 


\section{بر رسى تأثير هليكوباكتر ييلورى، خاى سياه و جوش شيرين بر روى متابوليسم آهن و بقاى رده سلولى MDCK}

داريوش حامدى اصل '، دكتر بابكى رحمانى'، دكتر تقى ناصريور فريور '، دكتر فاطمه حاج منوجهرى'، دكتر امير يِيمانى'

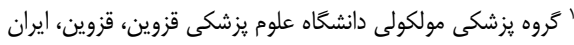

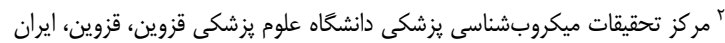

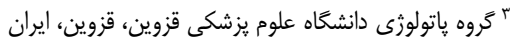

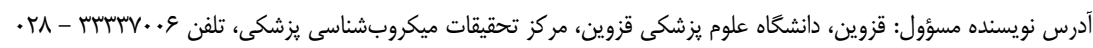

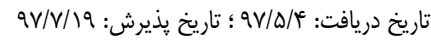

زمينه: كمخونى فقر آهن شايعترين اختلال تغذيهاى در جهان مىباشد. رثيم غذايى و عفونت هليكوباكترييلورى از جمله عوامل مطرح در بروز ايـن اختلال مى إشند.

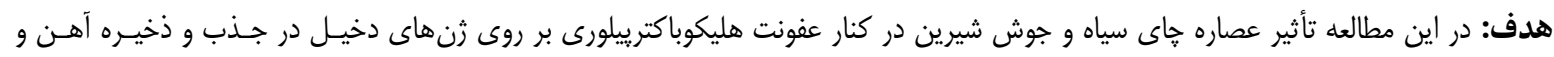
تكثير سلولى مورد بررسى قرار كرفته است.

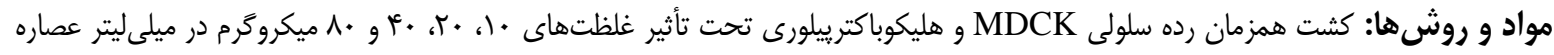

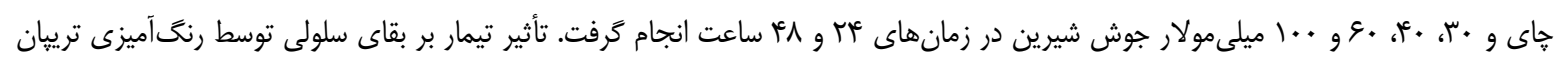

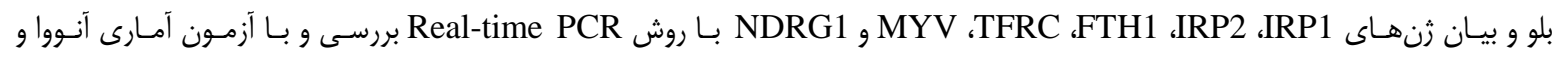
نمونهاي مستقل تى تحليل كَرديد.

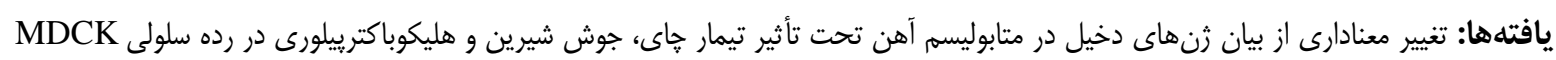

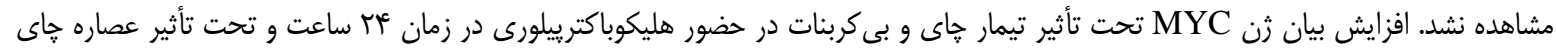

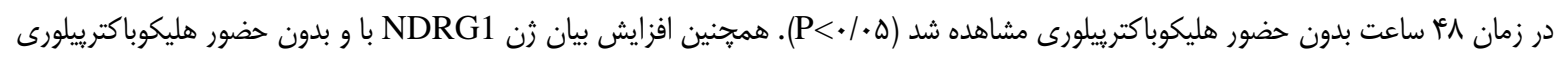

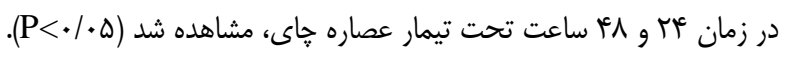

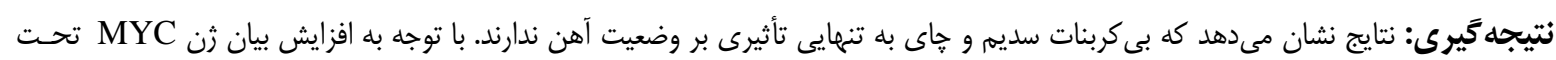

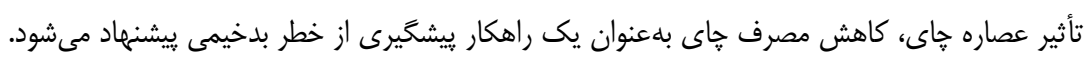

كليدوازهها: آهن، خاى، جوش شيرين، هليكوباكترييلورى

اسيديته معده بهواسطه جوش شيرين مانع از جـذب مـؤثر

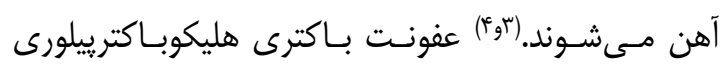

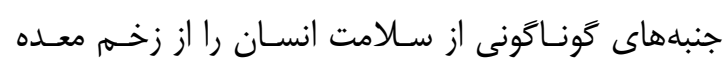

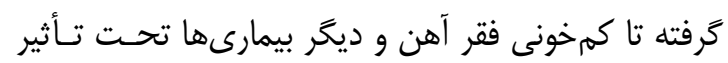

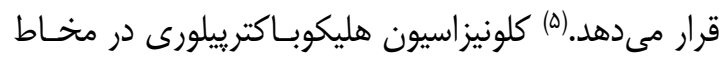

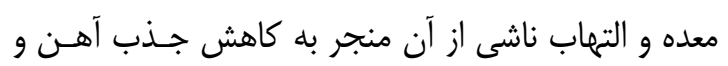

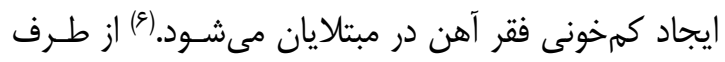

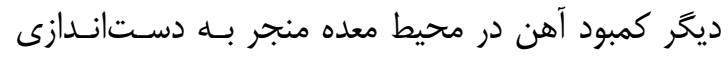

مقدمه:

متابوليسـم آهـن انسـان مجموعـهاى از فراينـدهـاى

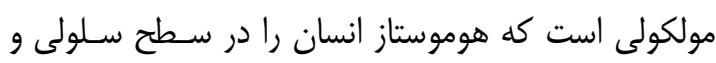

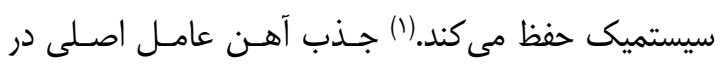

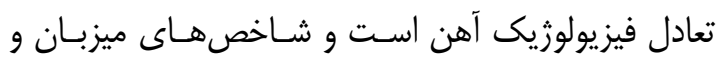

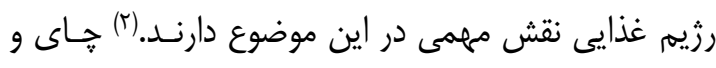

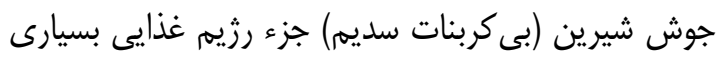

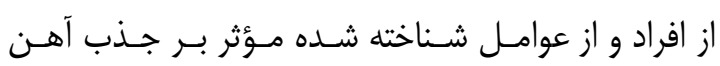

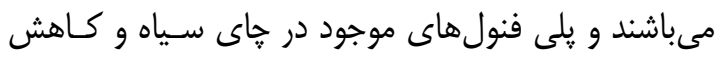




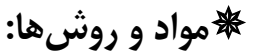

MDCK (Madin-Darby canine kidney)cells رده سلولى

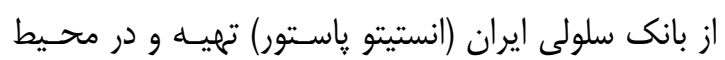

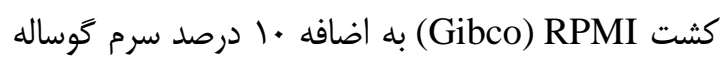
ه. و • (Gibco) FBS)

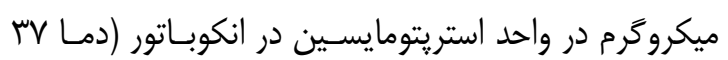

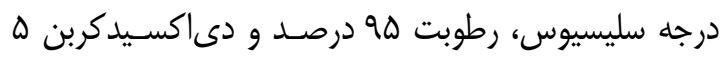
درصد) تا رسيدن به رشد مطلوب كشت داده شد. سلولها

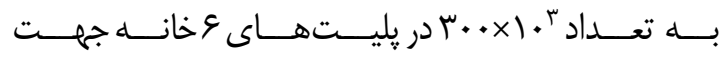

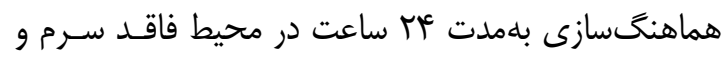

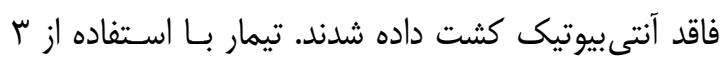
ميلىليتر محـيط كشـت RPMI حـاوى سب ميلـى مــولار

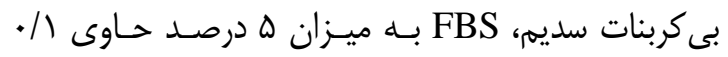

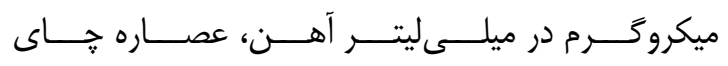
(Sigma-T5550)

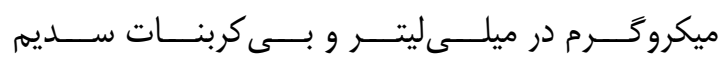
(Sigma-S5761)

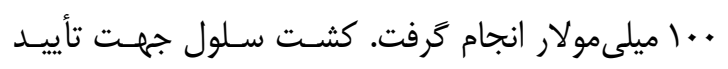

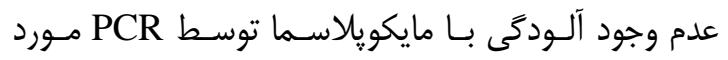
بررسى قرار كرفت و نتيجه منفى بود. جهت تعيين ميـزان

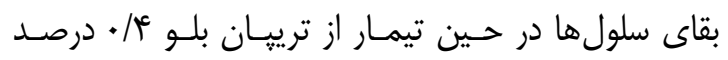

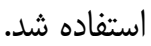

با توجه به اين كه تأثير بـى كربنـات از طريـق تغييـرات

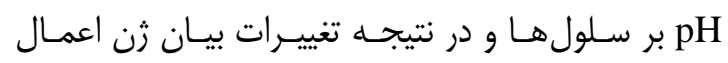

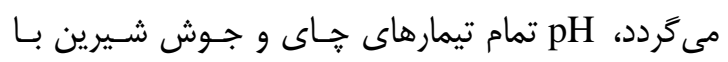

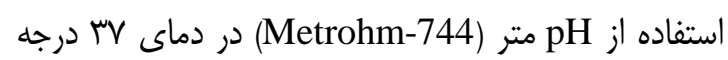
داخل انكوباتور دىاكسيد كربن انجام ترفت. سـويه هليكوبـاكترييلورى ATCC 26695 از 260

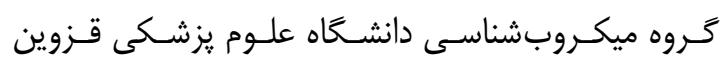

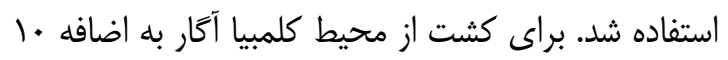

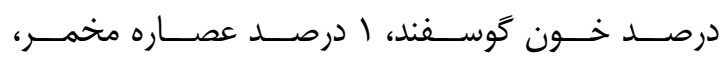

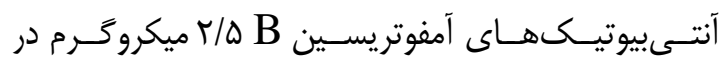

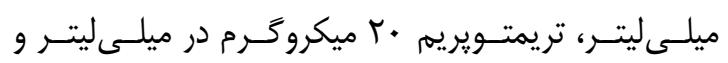

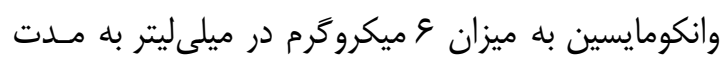

هليكوباكترييلورى به سـلولهـاى معـده جهـت بـهدسـت

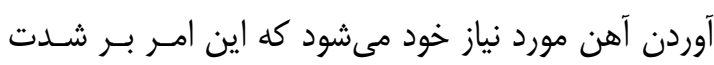
التهاب ناشى از عفونت مى افز ايد.

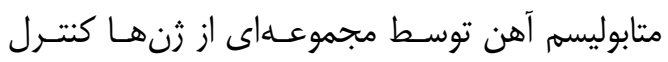

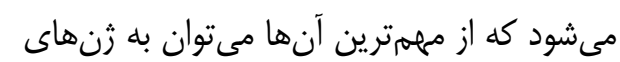
(Iron regulatory protein 1; IRP1) , (Iron regulatory protein 2; IRP2) g(Transferrin receptor chain; TFRC) (ㅅ). اشاره كرد (Ferritin transferrin heavy1; FTH1) هر كدام از اين ثن ها بلنوبه خود عملكردهاى ديخرى نيز در فرايندهاى سلولى دارند و كاهش يا افزايش بيـان ايـن إنـ

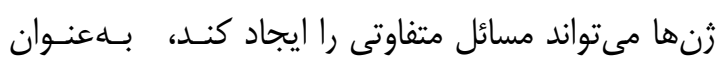

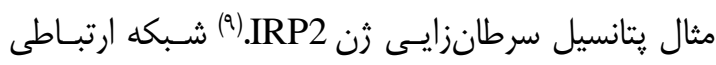

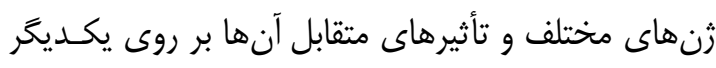

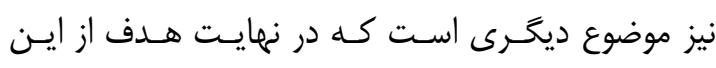

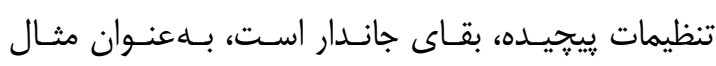

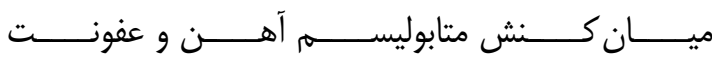

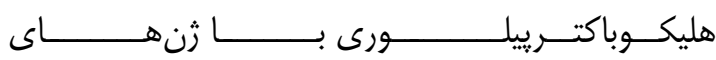
(N-Myc downstream regulated1) NDRG1

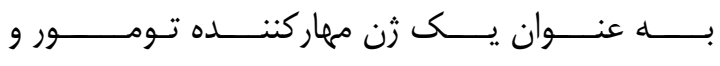
v-myc avian myelocytomatosis viral oncogene

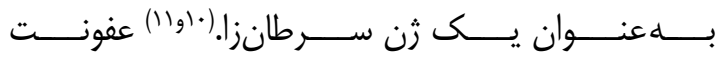

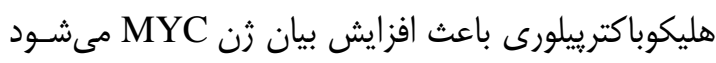

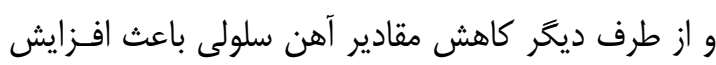

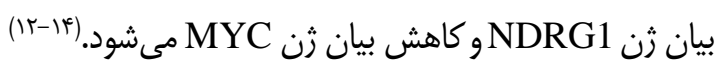

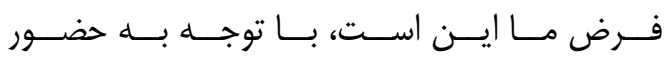

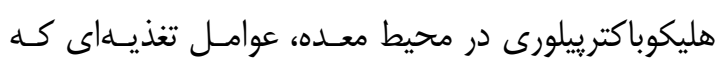

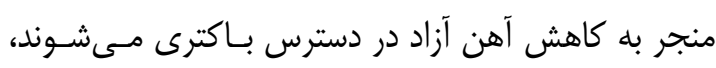

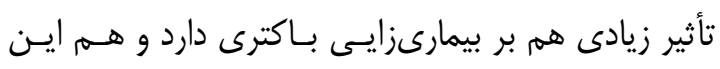

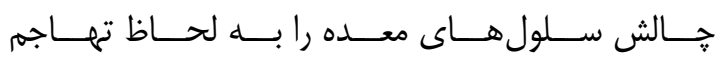

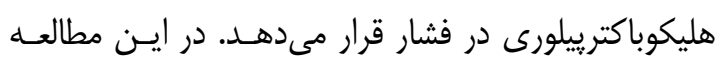

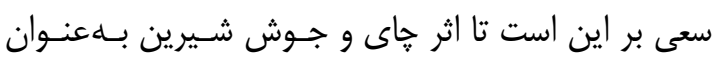

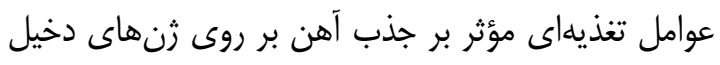

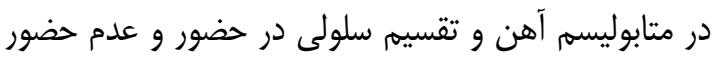

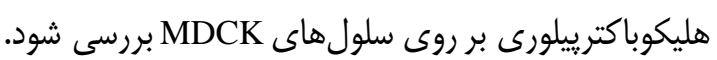


جهت انجام PCR بيان زن، ه/ تا س لاندا CDNA،

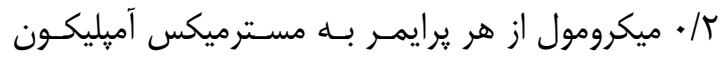
(RealQ Plus 2x Master Mix Green)

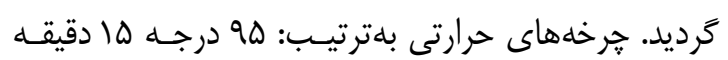

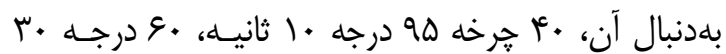

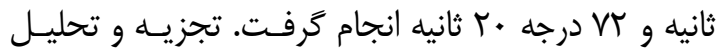
نتايج توسط نرمافزار Rotor-Gene Q Series Software

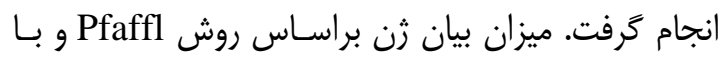

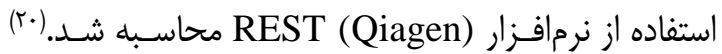

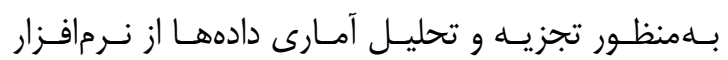

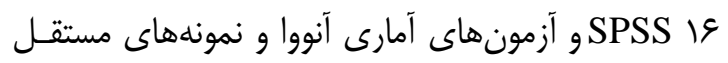

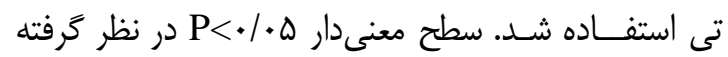

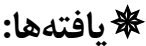

تيمار سلولها با عصاره خاى و بـى كربنـات سـديم در

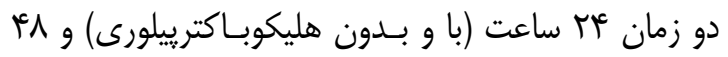

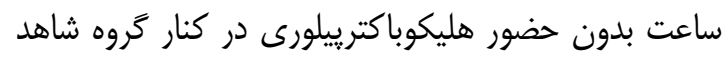
بلهورت سه كانه انجام گرفت. جهت بررسى اثـر شـرايط

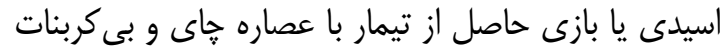
سديم pH محيط كشت پِ يس از تيمار در شرايط انكوبـاتور

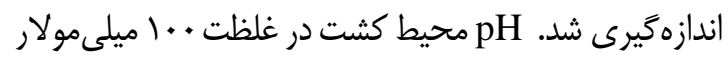

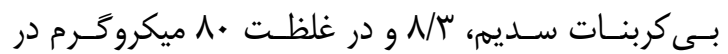
ميلى ليتر عصاره خاى، ه/ ع بود (شكل ا-الف).

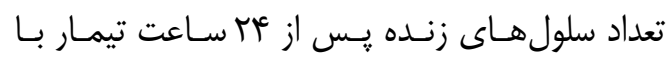

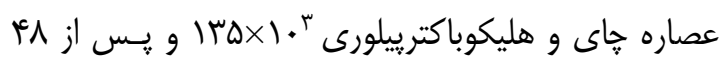

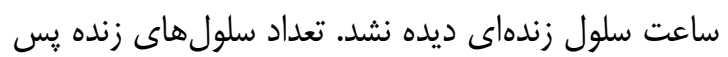

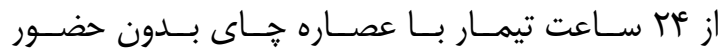

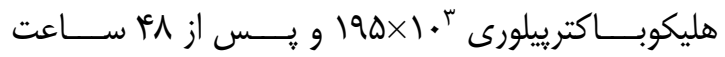

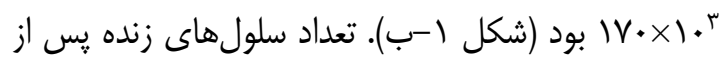

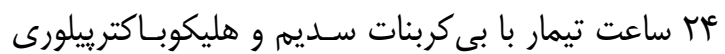

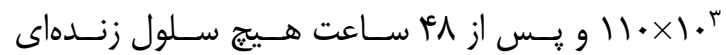

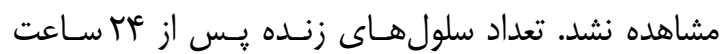

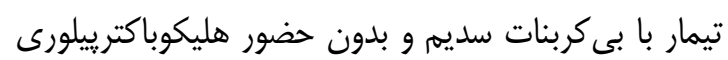

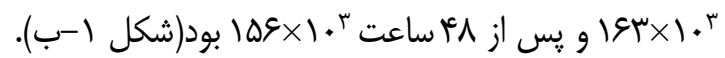

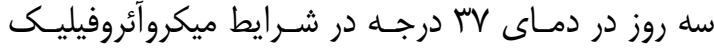

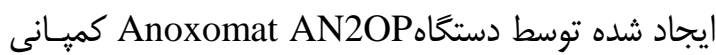

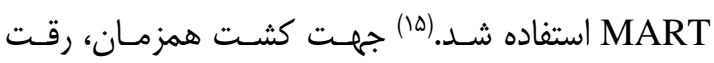
متناسب از بـاكترى بـا MOI 10:1 (نسـبت بـاكترى بــهـ سلول) در محيط كشت RPMI تهيه شد. جهت اسـتخراج

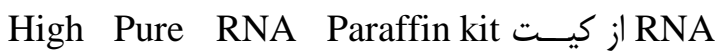

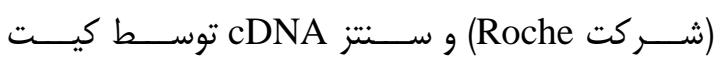

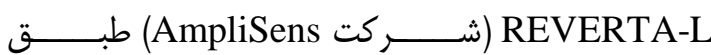
دستور العمل انجام كرفت.

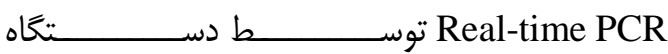

18S Rotor-Gene Q (Qiagen) ACTB وrRNA جهت NDRG1 و MYC TTFRC FTH1 ،IRP2 ،IRP1 بررسى اثر تيمار خاى و بـى كربنـات بـر روى متابوليسهم و

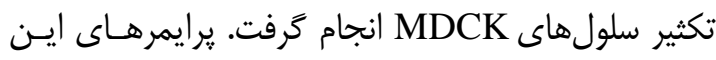
مطالعه براساس زنوم Canis lupus familiaris توسط كئ

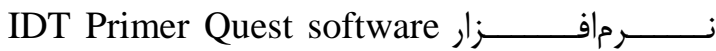
طراحسى (Integrated DNA Technologies, Inc) شدند كه ليست آنها در جدول شماره ا آورده شده است.

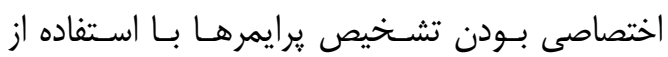

(Basic Local Alignment Search; BLAST) Tool (NCBI) GenBank database توالى كه با اين آزمون مداخله كند شناسايى نشد.

جدول ا - نام، توالى و اندازه برايمرهاى مورد بر رسى

\begin{tabular}{|c|c|c|c|}
\hline ثن & توالى يرايمر & قطعه & 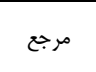 \\
\hline 18S - NM_001048082.1 & $\begin{array}{l}\text { CTAGTGATCCCTGAGAAGTTCC } \\
\text { ATGTCTGCTTTCCTCAATACC }\end{array}$ & $143 \mathrm{bp}$ & (19) \\
\hline ACTB - NM_001195845.2 & $\begin{array}{l}\text { GGCATCCTGACCCTGAAGTA } \\
\text { GGGGTGTTGAAAGTCTCGAA }\end{array}$ & 203 bp & (IV) \\
\hline TFRC-NM_001003111.1 & $\begin{array}{l}\text { CACTGAATGGCTAGAGGGATAC } \\
\text { GCAGAAACCTTGAAGTTGCTG }\end{array}$ & 105 bp & اين مطالعه \\
\hline FTH1-NM_001193656.1 & $\begin{array}{l}\text { GTCTTACGTCTACTTGTCCATG } \\
\text { TTTCTCAGCATGTTCCCTCTC }\end{array}$ & 115 bp & اين مطالعه \\
\hline IRP1-NM_001320941.1 & $\begin{array}{l}\text { CTACAGGCTCTTGGGAAATC } \\
\text { ACTCCACAAACTTGCCTACTAC }\end{array}$ & $107 \mathrm{bp}$ & اين مطالعه \\
\hline IRP2 - NC_000915.1 & $\begin{array}{l}\text { CAACCAGTGCCTGAACCTG } \\
\text { ATGAGCCATTCCAGTTCCAG }\end{array}$ & 144 bp & اين مطالعه \\
\hline MYC - NM_001003246.2 & $\begin{array}{l}\text { TCGCCTATTTGGGAAGACAC } \\
\text { AAGCTGACGTTGAGAGGCAT }\end{array}$ & $141 \mathrm{bp}$ & $(\backslash \Lambda)$ \\
\hline NDRG1- NC_000915.1 & $\begin{array}{l}\text { AGGGCCTCGTCCTTATCAAC } \\
\text { GACCACCTCCACGTTGTTCT }\end{array}$ & 152 bp & (19) \\
\hline
\end{tabular}


هليكوباكترييلورى و در غلظتهاى • أ و •1 ميكروگرم در

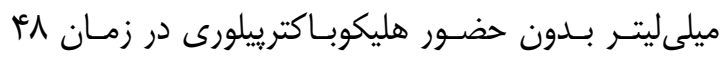

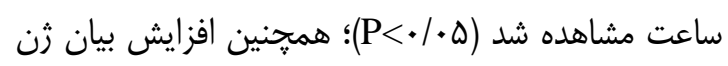
NDRG1

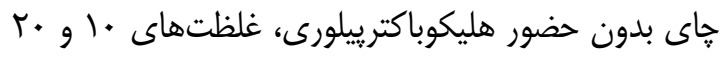

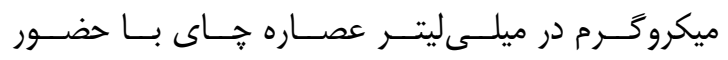

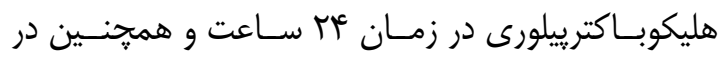

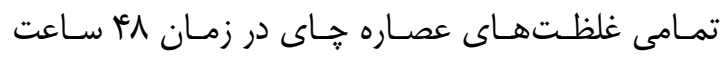

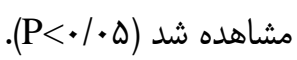

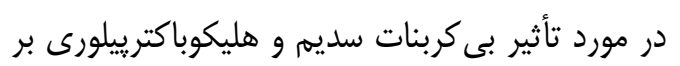

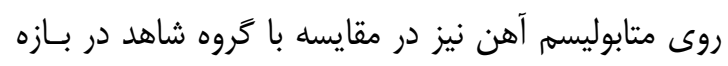

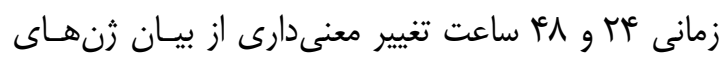

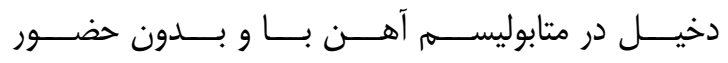

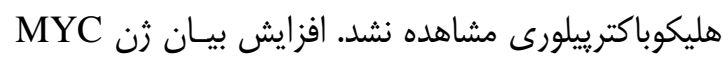

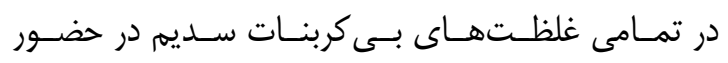

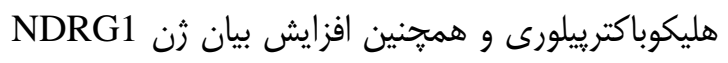

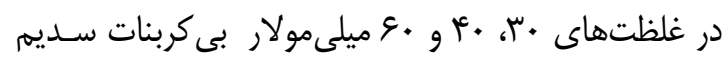

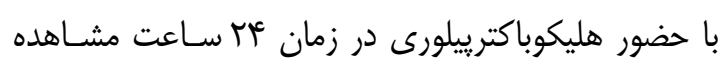

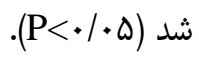
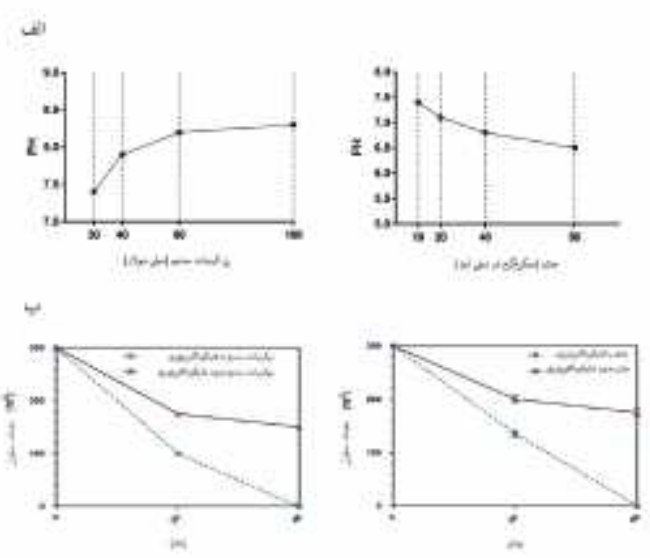

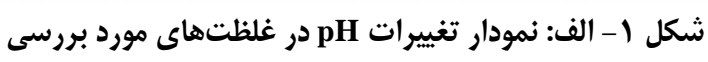

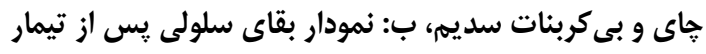

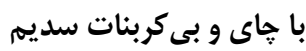

در بررسى تأثير عصاره خاى و هليكوبـاكتر ييلورى بـر

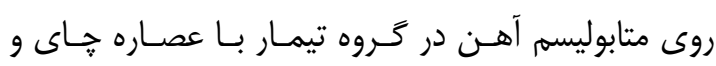

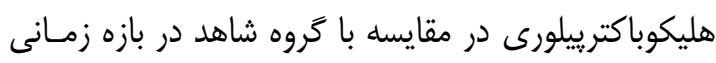

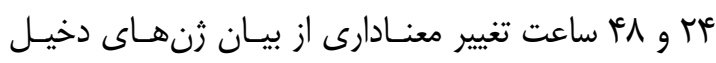

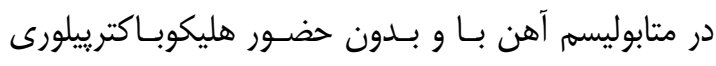

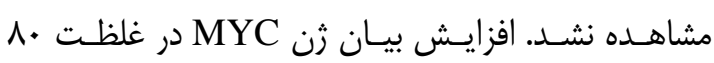

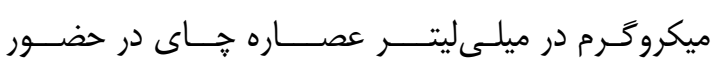

شكل r- نمودار تغييرات بيان ثنهاى IRP1,IRP2,TFRC,FTH,MYC,NDRG1 در تيمار با خاى و بىكربنات سديم

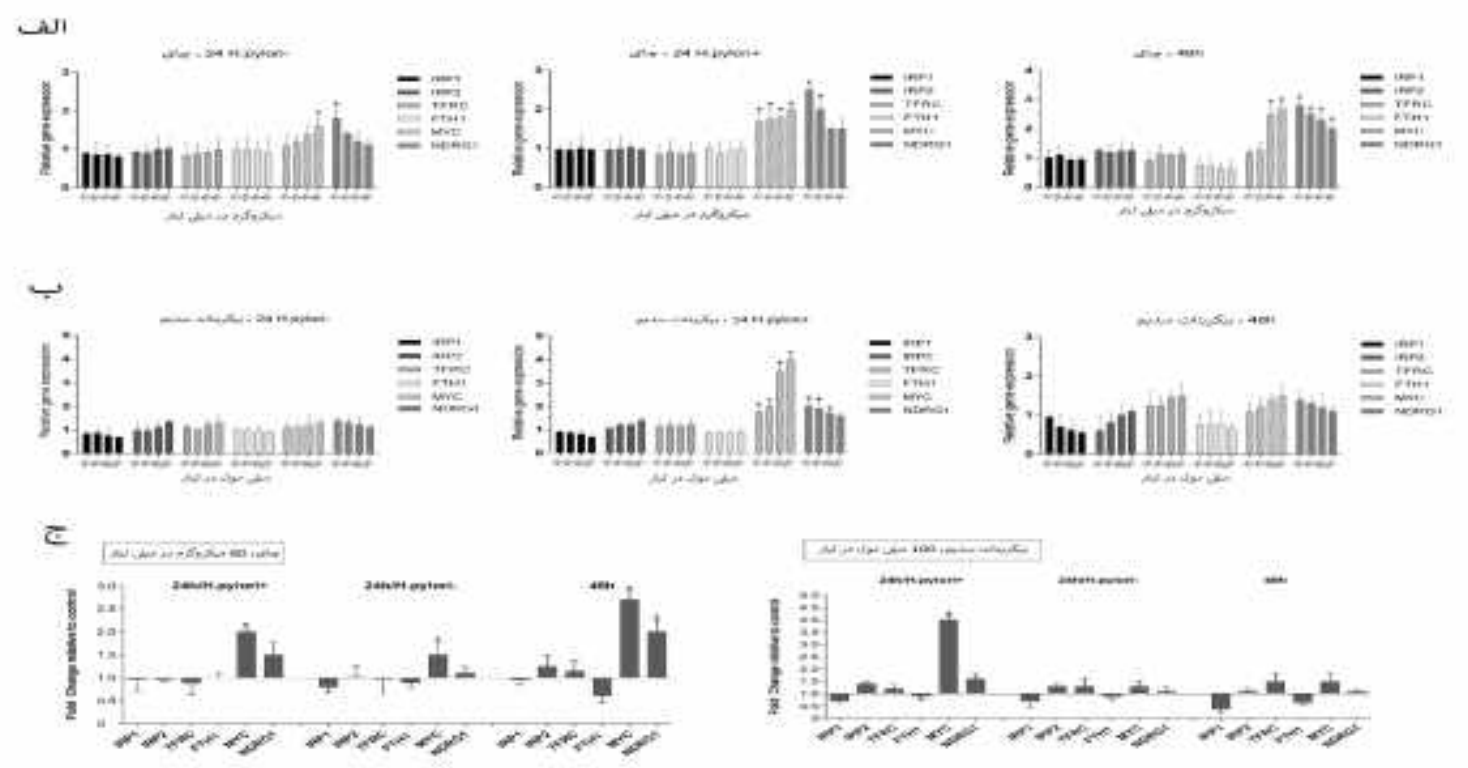




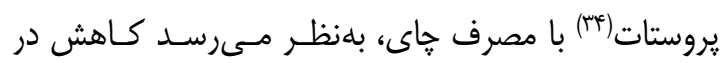

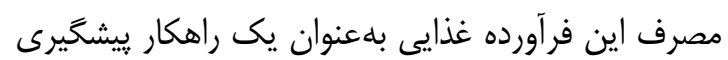
از خطر، خالى از فايده نباشد.

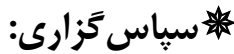

اين مقاله، حاصل قسمتى از طرح تحقيقاتى مصوب به

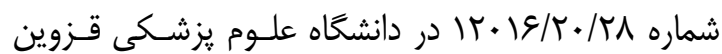
مىباشد. بدينوسيله مراتب قدردانى خود را از مساعدتهاى مسئولين محترم يزوهشى دانشخاه ابر از مى داريه.

\section{مراجع:}

1. Chifman J, Laubenbacher R, Torti SV. A systems biology approach to iron metabolism. Adv Exp Med Biol 2014; 844: 201-25. doi: 10.1007/978-1-4939-2095-2_10.

2. Pereira RC, Diniz A.dS, Ferreira LOC. New findings on iron absorption conditioning factors. Brazilian $\mathrm{J}$ Mother Child Health 2004; 4(3): 8-241.

3. Hurrell RF, Reddy M, Cook JD. Inhibition of non-haem iron absorption in man by polyphenolic-containing beverages. Br J Nutr 1999; 81(4): 289-95. doi: 10. 1017/ S0007114599000537.

4. O'Neil-Cutting MA, Crosby WH. The effect of antacids on the absorption of simultaneously ingested iron. JAMA 1986; 255(11): 1468-70 doi: 10.1001/jama.255.11. 1468.

5. Franceschi F, Zuccala G, Roccarina D, Gasbarrini A. Clinical effects of Helicobacter pylori outside the stomach. Nat Rev Gastroenterol Hepatol 2014; 11(4): 234-42. doi: 10.1038/nrgastro.2013.243.

6. Burns M, Muthupalani S, Ge Z, Wang TC, Bakthavatchalu V, Cunningham $\mathrm{C}$, et al. Helicobacter pylori infection induces anemia, depletes serum iron storage, and alters local iron-related and adult brain gene expression

\section{بحث و نتيجهَيرى}

ارتباط رزيم غذايى با بروز بيمارىهاى مختلف همواره مطرح بوده و مواد غذايى هـر كـدام براسـاس ماهيتشـان بــان اثرهاى خاص خود را بر روى سلامتى انسان مس كذارنســـ اين كه جاى و جوش شيرين تا جه حد باعـث اخـتالال در

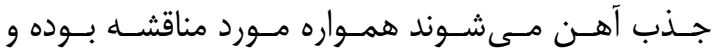

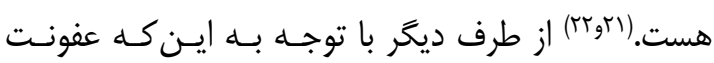

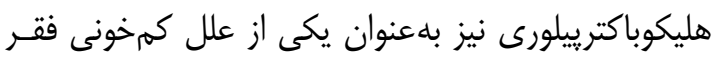

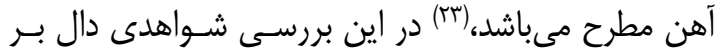

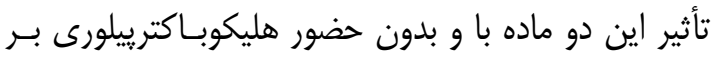

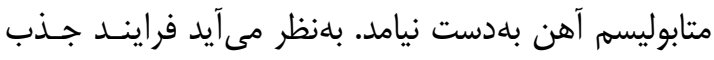

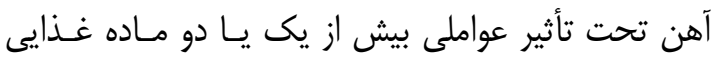
باشد و هيج كدام از اين مواد بلهتنهايى نمىتوانند منجر بــهـ

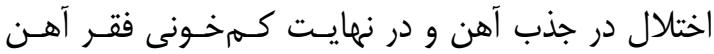

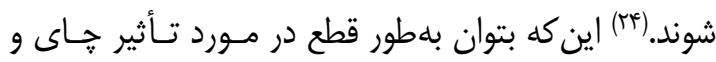

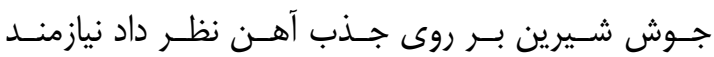
مطالعههاى بالينى بيشتر و طولانى است.

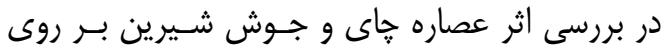

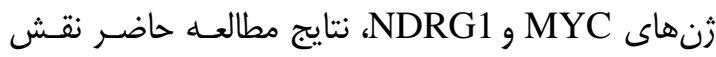

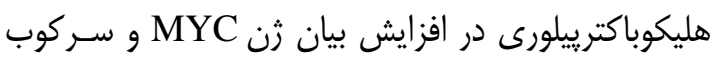

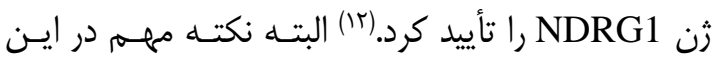

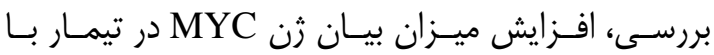

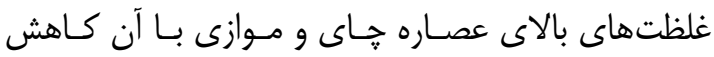

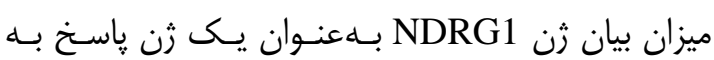

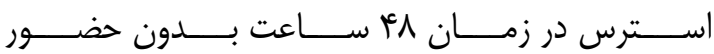

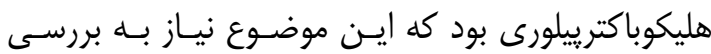
بيشترى دارد، هرا كه زن MYC بهعنوان يك زن داراى

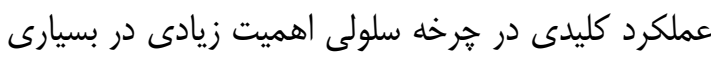

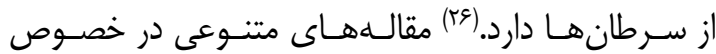

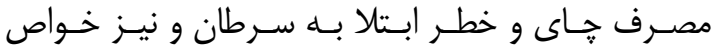

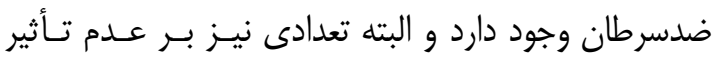

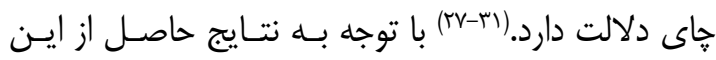

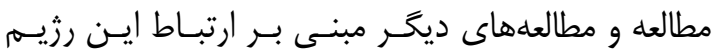

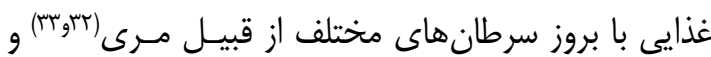


in male INS-GAS mice. PLoS One 2015; 10(11): e0142630. doi: 10.1371/journal.pone. 0142630.

7. Noto JM, Gaddy JA, Lee JY, Piazuelo MB, Friedman DB, Colvin DC, et al. Iron deficiency accelerates Helicobacter pylori induced carcinogenesis in rodents and humans. J Clin Invest 2013; 123(1): 479-92. doi: 10.1172/JCI64373.

8. Cairo G, Recalcati S. Iron-regulatory proteins: molecular biology and pathophysiological implications. Expert Rev Mol Med 2007; 9(33): 1-13. doi: 10.1017/ S1462399407000531.

9. Maffettone C, Chen G, Drozdov I, Ouzounis C, Pantopoulos K. Tumorigenic properties of iron regulatory protein 2 (IRP2) mediated by its specific 73-amino acids insert. PLoS One 2010; 5(4): e10163. doi: 10. 1371/journal.pone.0010163.

10. Fraser A. Essential human genes. Cell Syst 2015; 1(6): 381-2. doi: 10.1016/j.cels. 2015.12.007.

11. Kovacevic Z, Fu D, Richardson DR. The iron-regulated metastasis suppressor, Ndrg-1: identification of novel molecular targets. Biochim Biophys Acta 2008; 1783(10): 198192. doi: 10.1016/j.bbamcr.2008.05.016.

12. Kim SS, Meitner P, Konkin TA, Cho YS, Resnick MB, Moss SF. Altered expression of Skp2, c-Myc and p27 proteins but not mRNA after $H$. pylori eradication in chronic gastritis. Mod Pathol 2006; 19(1): 49-58. doi: 10. 1038/modpathol.380047613.

13. Le NT, Richardson DR. Iron chelators with high antiproliferative activity upregulate the expression of a growth inhibitory and metastasis suppressor gene: a link between iron metabolism and proliferation. Blood 2004; 104(9): 2967-75. doi: 10.1182/ blood-2004-05-1866.
14. Kyriakou D, Eliopoulos AG, Papadakis A, Alexandrakis M, Eliopoulos GD. Decreased expression of c-myc oncoprotein by peripheral blood mononuclear cells in thalassaemia patients receiving desferrioxamine. Eur J Haematol 1998; 60(1): 21-7. doi: 10.1111/j.1600-0609.1998. tb00992.x.

15. Blanchard TG, Nedrud JG. Laboratory maintenance of Helicobacter species. Curr Protoc Microbiol 2006; Chapter 8: Unit8B 1. doi: 10.1002/9780471729259.mc08b01s00.

16. Robriquet $\mathrm{F}$, Lardenois A, Babarit C, Larcher $\mathrm{T}$, Dubreil L, Leroux I, et al. differential gene expression profiling of dystrophic dog muscle after MuStem cell transplantation. PLoS One 2015; 10(5): e0123336. doi: 10.1371/journal.pone. 0123336.

17. Basu D, Walkiewicz MP, Frieman M, Baric RS, Auble DT, Engel DA. Novel influenza virus NS1 antagonists block replication and restore innate immune function. J Virol 2009; 83(4): 1881-91. doi: 10.1128/JVI.01805-08.

18. Angstadt AY, Motsinger-Reif A, Thomas R, Kisseberth WC, Guillermo Couto C, Duval DL, et al. Characterization of canine osteosarcoma by array comparative genomic hybridization and RT-qPCR: signatures of genomic imbalance in canine osteosarcoma parallel the human counterpart. Genes Chromosomes Cancer 2011; 50(11): 859-74. doi: $10.1002 /$ gcc. 20908 .

19. Bruun CS, Jaderlund KH, Berendt M, Jensen KB, Spodsberg EH, Gredal H, et al. A Gly98Val mutation in the N-Myc Downstream regulated gene 1 (NDRG1) in Alaskan Malamutes with polyneuropathy. PLoS One 2013; 8(2): e54547. doi: 10. 1371/journal.pone.0054547. 
20. Pfaffl MW. A new mathematical model for relative quantification in real-time RTPCR. Nucleic Acids Res 2001; 29(9): e45.

21. Fakhri Y, Amanidaz N, Zandsalimi Y, Dadar M, Moradi A, Moradi B, et al. Association between sodium bicarbonate consumption and human health: a systematic review. Int J Med Res Health Sci 2016; 5(8): 22-9.

22. Delimont NM, Haub MD, Lindshield BL. The impact of tannin consumption on iron bioavailability and status: a narrative review. Curr Dev Nutr 2017; 1(2): 1-12. doi: 10.3945/ cdn.116.000042.

23. Ciacci C Sabbatini F, Cavallaro R, Castiglione F, Di Bella S, Iovino $\mathrm{P}$, et al. Helicobacter pylori impairs iron absorption in infected individuals. Dig Liver Dis 2004; 36(7): 455-60. doi: 10.1016/j.dld.2004.02. 008.

24. Hurrell R, Egli I. Iron bioavailability and dietary reference values. Am J Clin Nutr 2010; 91(5): 1461S-7. doi: 10.3945/ajcn. 2010.28674F.

25. Beck KL, Conlon CA, Kruger R, Coad J. Dietary determinants of and possible solutions to iron deficiency for young women living in industrialized countries: a review. Nutrients 2014; 6(9): 3747-76. doi: 10.3390/ nu6093747.

26. Gabay M, Li Y, Felsher DW. MYC activation is a hallmark of cancer initiation and maintenance. Cold Spring Harb Perspect Med 2014; 4(6). pii: a014241. doi: 10.1101/ cshperspect.a014241.

27. Montague JA, Butler LM, Wu AH, Genkinger JM, Koh WP, Wong AS, et al. Green and black tea intake in relation to prostate cancer risk among Singapore Chinese. Cancer Causes Control 2012; 23(10): 1635-41. doi: 10.1007/s10552-012-
0041-8.

28. Konarikova K, Jezovicova M, Kerestes J, Gbelcova H, Durackova Z, Zitnanova I. Anticancer effect of black tea extract in human cancer cell lines. Springerplus 2015; 4: 127. doi: 10.1186/s40064-015-0871-4.

29. Su LJ, Arab L. Tea consumption and the reduced risk of colon cancer - results from a national prospective cohort study. Public Health Nutr 2002; 5(3): 419-25. doi: 10. 1079/PHN2001314

30. Ghaemi A, Mohmmadi I, Shoae Hassani A, Hamdi K, Ordouzadeh N. Inhibitory effect of green and black teas Ethyl acetate extracts on Helicobacter pylori the causative agent of peptic ulcers. J Qazvin Univ Med Sci 2010; 13(4) :12-8. [In Persian]

31. Miura K, Hughes MC, Arovah NI, van der Pols JC, Green AC. Black tea consumption and risk of skin cancer: an 11year prospective study. Nutr Cancer 2015; 67(7): 1049-55. doi: 10.1080/01635581. 2015.1073759 .

32. Zamora-Ros R, Lujan-Barroso L, Buenode-Mesquita HB, Dik VK, Boeing H, Steffen A, et al. Tea and coffee consumption and risk of esophageal cancer: the European prospective investigation into cancer and nutrition study. Int J Cancer 2014; 135(6): 1470-9. doi: 10.1002/ijc.28789.

33. Askari F, Kardoust parizi M, Rashidkhani B. Black tea and coffee intake and prostate cancer: A case-control study. Scientific J Ilam Univ Med Sci 2014; 22(6): 60-5. [In Persian] 34. Islami F, Pourshams A, Nasrollahzadeh D, Kamangar F, Fahimi S, Shakeri R, et al. Tea drinking habits and oesophageal cancer in a high risk area in northern Iran: population based case-control study. BMJ 2009; 338: b929. doi: 10.1136/bmj.b929. 